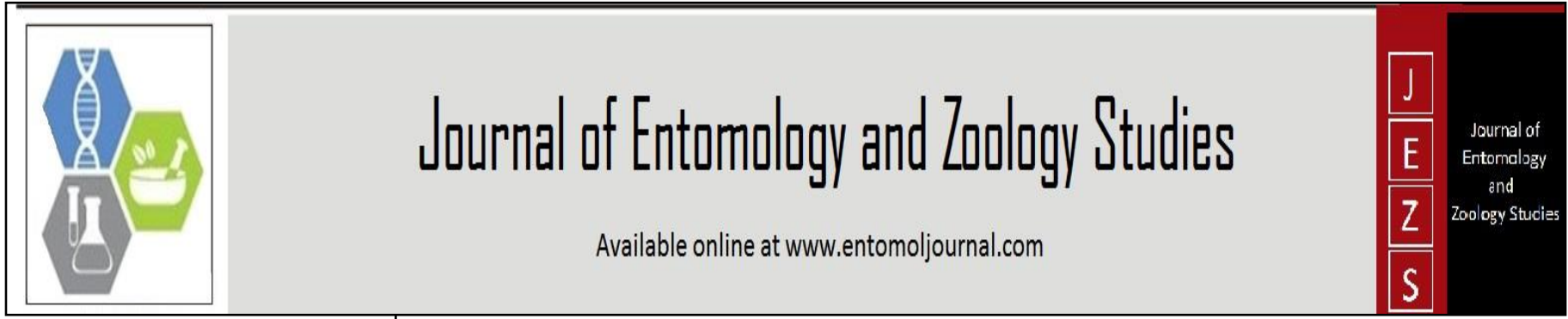

E-ISSN: 2320-7078

P-ISSN: 2349-6800

www.entomoljournal.com JEZS 2021; 9(1): 916-918 (C) $2021 \mathrm{JEZS}$

Received: 16-11-2020

Accepted: 18-12-2020

\section{S Ramesh}

Department of Agricultural

Entomology, Agricultural

College and Research Institute,

Tamil Nadu Agricultural

University, Madurai, Tamil

Nadu, India

\section{S Manisegaran}

Department of Agricultural

Entomology, Agricultural

College and Research Institute,

Tamil Nadu Agricultural

University, Madurai, Tamil

Nadu, India

\section{K Suresh}

Department of Agricultural Entomology, Agricultural

College and Research Institute,

Tamil Nadu Agricultural

University, Madurai, Tamil

Nadu, India

\section{P Saravana Pandian}

Department of Soil Science and

Agricultural Chemistry,

Tamil Nadu Agricultural

University, Agricultural College and Research Institute,

Madurai, Tamil Nadu, India

Corresponding Author:

S Ramesh

Department of Agricultural

Entomology, Agricultural

College and Research Institute,

Tamil Nadu Agricultural

University, Madurai, Tamil

Nadu, India

\section{Natural parasitism of greater wax moth, Galleria mellonella Linnaeus larvae by Apanteles galleriae Wilkinson in Madurai district, Tamil Nadu}

\author{
S Ramesh, S Manisegaran, K Suresh and P Saravana Pandian
}

DOI: https://doi.org/10.22271/j.ento.2021.v9.i1m.8262

\section{Abstract}

Apanteles galleriae Wilkinson, a larval parasitoid was observed from natural population of greater wax moth, Galleria mellonella Linnaeus larvae in Madurai region, Tamil Nadu, India. The per cent parasitisation and sex ratio (F: M) ranged from 9.09 to 23.08 per cent and 1:1 to 1: 1.40 respectively. Among different periods, high number (12) and parasitism (23.08\%) were noticed during November, followed by December 2019. Thereafter, the per cent parasitism declined in March 2019. A similar trend was also observed with regards to sex ratio (F: M).

Keywords: Galleria mellonella, Apanteles galleriae, greater wax moth larvae, bee keeping and parasitism

\section{Introduction}

Greater wax moth is a very dangerous threat to bee keeping industry. It causes 60 to 70 per cent damage in bee keeping sector of developed countries (Paddock, 1918; Hanumanthaswamy et al., 2009) ${ }^{[2,5]}$. It destroys a large number of combs in the colony, wax foundation sheets, stored combs and stored hive products. Management of greater wax moth is unavoidable thing in bee keeping industry. Researchers have identified some biological control agents viz., Bacillus thuringiensis, Solonopsis invicta and Solonopsis germinita Fab., Apanteles galleriae and Bracon hebetor. However, the use of bio control agents are still lacking on commercial purpose (Kwadha et al., 2017) ${ }^{[4]}$. Among these, the hymenopteran larval parasitoid $A$. galleriae was found to be a prominent natural enemy of greater wax moth (Hanumanthaswamy and Rajagopal, 2017) ${ }^{[3]}$. A. galleriae belongs to the family braconidae: sub- family microgastrinae in the Hymenopteran order (Galindo-Cardona, 2019) ${ }^{[1]}$. It is a solitary koinobiont early-instar larval endoparasitoid of G. mellonella (Shimamori 1987) ${ }^{[6]}$. The duration of the incubation, larval, pupal and total developmental period of the A. galleriae were 3.2, 12.7, 7.7 and 23.6days, respectively (Verma and Desh Raj, 1997) ${ }^{[8]}$. Generally emergences of males were higher than the female (Subash Chander, 1995) ${ }^{[7]}$. Hence, an investigation was carried out to assess the nature and extent of parasitism of A. galleriae in Madurai district, Tamil Nadu.

\section{Materials and Methods}

During survey from October 2019 to March 2020 G. mellonella larvae were collected from five locations viz., Alanganallur, Vadipatti, Melur, Madurai West and Madurai East. From each place one greater wax moth infested hive was selected and larvae were collected. The collected larvae were brought to insect mass culture laboratory, Department of Agricultural Entomology, AC \& RI, Madurai and reared. Adult parasitoids that emerged from the larvae were collected and preserved in $70 \%$ ethanol. Then, the number of parasitoids emerged and sex ratio were observed. The parasitoid samples were send to ICAR-NBAIR, Bangalore for Identification. Images of $A$. galleriae were captured using Stereo zoom microscope in the Department of Bio-technology, Centre of Innovation, Agricultural College and Research Institute, Madurai. The extent of per cent parasitism was calculated and the relationship between A. galleriae and $G$. mellonella was subjected to regression analysis using SPSS statistical tool. 


\section{Results and Discussion}

\section{Identification of $A$. galleriae}

The parasitoid was got identified as Apantelles galleriae from ICAR-NBAIR, Bangalore and it was a tiny black parasitoid (Plate 1. a). Adult body length measured about $40 \mathrm{~mm}$ with long antenna (Plate 1.c). A deep brown stigma was noticed at the proximal end of fore wings. Legs were pale yellow in colour except coxae which were dark brown. Abdomen was pale brown in colour with a translucent pale-yellow band. Females were identified with a long ovipositor (Plate 1.c \&1.d). The present finding on the description of the parasitoid is in accordance with the reports of Whitfield et al. (2001) ${ }^{[10]}$; Hanumanthaswamy and Rajagopal (2017) ${ }^{[3]}$.

\section{Per cent parasitisation and sex ratio of $A$. galleriae}

From the table 1 , it is evident that there were significant differences in per cent parasitisation and sex ratio at different periods. The extent of parasitism ranged from 9.09 to 23.33 per cent. Among different periods, high number (12) and parasitisation $(23.08 \%)$ of $A$. galleriae was recorded during
November 2019, followed by December 2019. A similar trend was observed with regard to sex ratio (F: $\mathrm{M}$ ) also. No parasitism was observed during the month of March 2020.

The table 2 revealed that a highly significant correlation was found between number of $G$. mellonella larvae and $A$. galleriae (Fig. 1). Similar result was also obtained in the case of relationship between number of $G$. mellonella larvae and per cent parasitism. This present finding is in agreement with reports of several authors: Shimamori (1987) ${ }^{[6]}$ reported that A. gallariae 15 per cent parasitism on G. mellonella larvae. Galindo-Cardona et al. (2019) ${ }^{[1]}$ observed that $27 \%$ A. galleriae emerged from lesser wax moth (Achroia grisella Fab.) larvae. Hanumanthaswamy and Rajagopal (2017) [3] reported that parasitism ranged from 12 to $54.44 \%$ and highest sex ratio ( $\mathrm{F}: \mathrm{M}$ ) ranged from 1: 1 to $1: 1.5$ depending upon the environmental conditions. Vinay Kumar (2019) ${ }^{[9]}$ reported that the per cent parasitisation of A. galleriae ranged from 5 to 40 at different periods. Subash Chandar (1995) ${ }^{[7]}$ observed that $14.29 \%$ to $44 \%$ parasitisation of A. galleriae on greater wax moth.

Table 1: Parasitism by A. galleriae on G. mellonella larvae at different periods

\begin{tabular}{|c|c|c|c|c|}
\hline Month/Year & No. of. G. mellonella larvae & No. of. A. galleriae emergence & Per cent parasitisation & Sex ratio F:M \\
\hline October 2019 & 42 & 08 & 19.05 & $1: 1.00$ \\
\hline November 2019 & 52 & 12 & 23.08 & $1: 1.40$ \\
\hline December 2019 & 40 & 09 & 22.50 & $1: 1.25$ \\
\hline January 2020 & 32 & 04 & 12.50 & $1: 1.00$ \\
\hline February 2020 & 22 & 02 & 9.09 & $1: 1.00$ \\
\hline March 2020 & 8 & 00 & 0.00 & $0: 0$ \\
\hline
\end{tabular}

Table 2: Relationship between G.mellonella larvae and A. galleriae

\begin{tabular}{|c|c|c|c|}
\hline Parameters & "r" & Regression equation & P> and significance \\
\hline No. of. G.mellonella larvae vs No. of. A. galleriae adult emergence & 0.93 & $\mathrm{Y}=13.26+3.32 \mathrm{X}$ & $<0.01 * *$ \\
\hline No.of. G.mellonella larvae vs Per cent parasitisation & 0.94 & $\mathrm{Y}=8.20+1.70 \mathrm{X}$ & $<0.01^{* *}$ \\
\hline
\end{tabular}

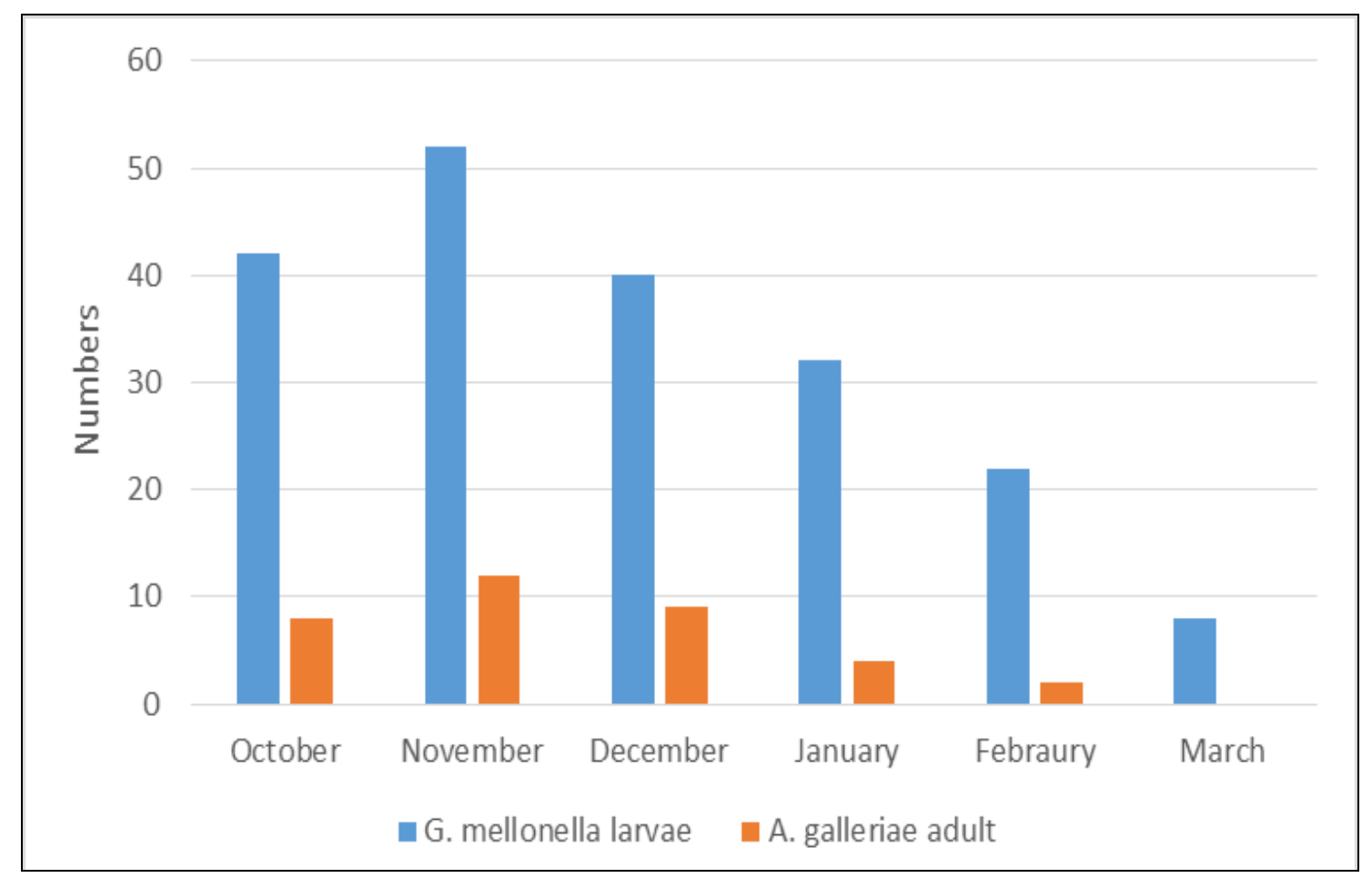

Fig 1: Relationship between G. mellonella larvae and A. galleriae in different periods 


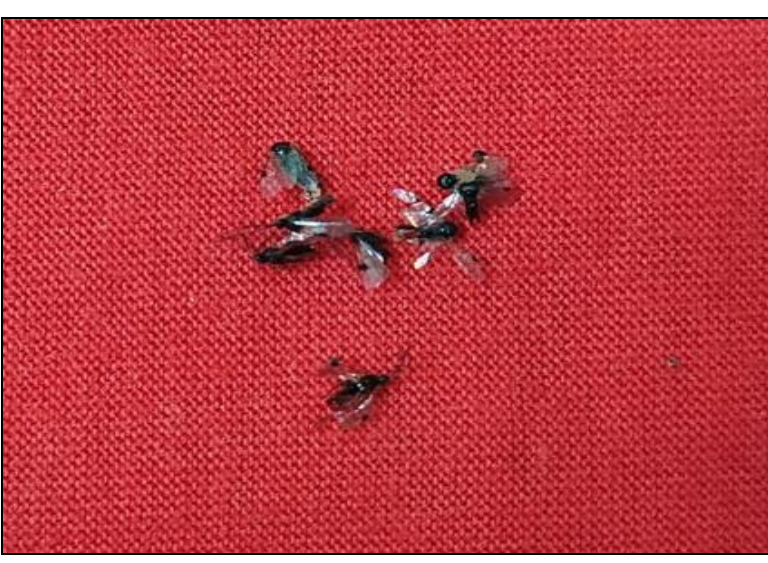

a. Adult

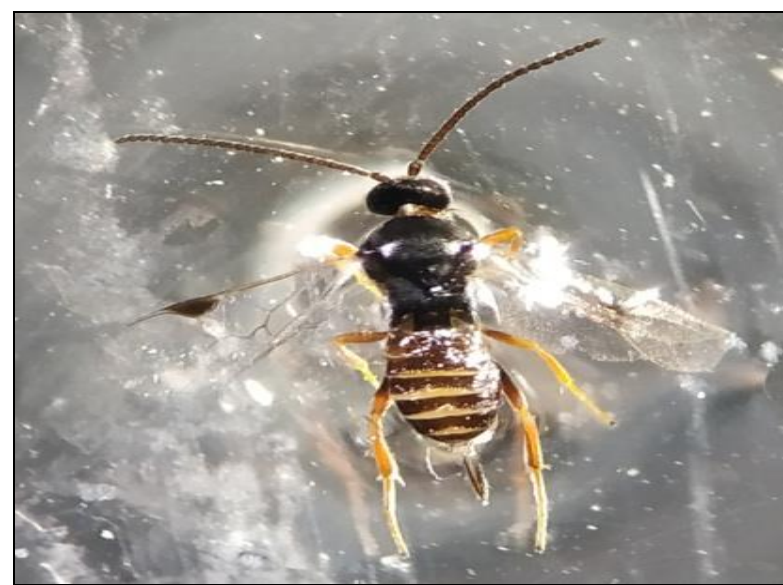

c. Female of A. galleriae

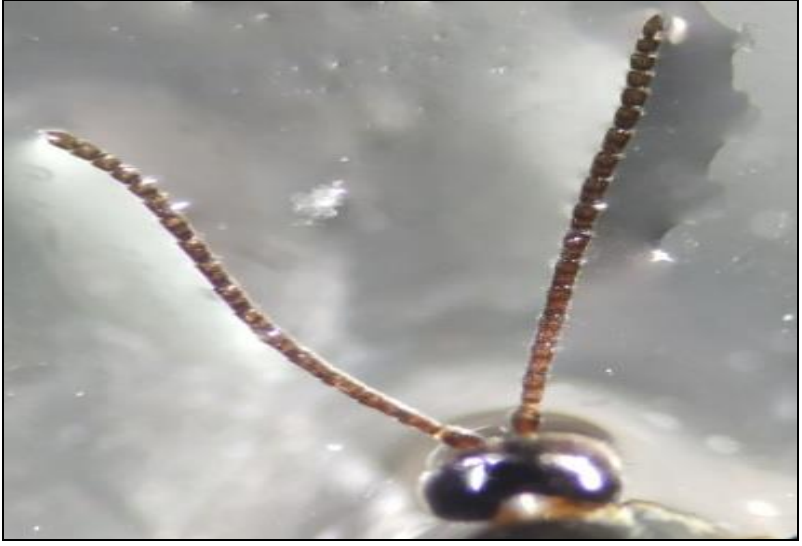

b. Antennae

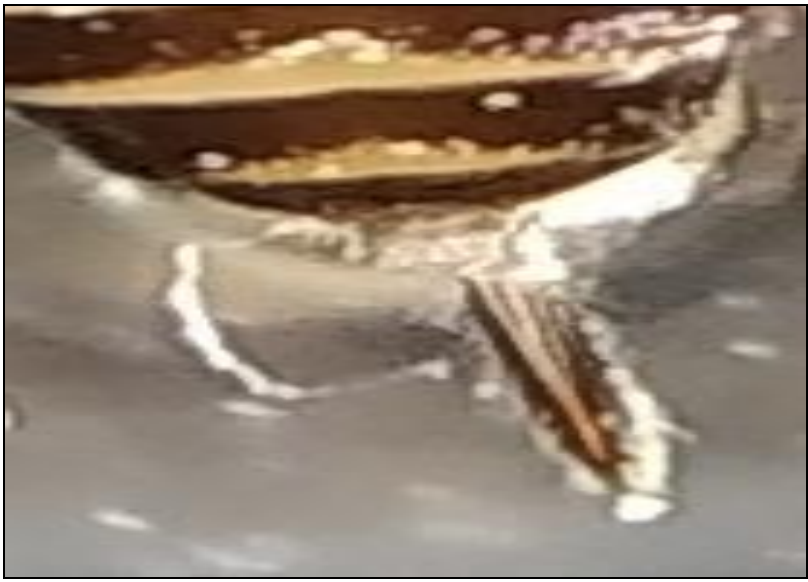

d. Ovipositor

Plate 1: Images of A. gallariae

\section{Conclusion}

As the natural occurrence, the extent of parasitism by $A$. galleriae and the relationship between greater wax moth larvae and A. galleriae is found promising, an attempt may be made to mass multiply A. galleriae for field release.

\section{Acknowledgement}

The authors are thankful to Dr. Ankita Gupta, Senior scientist, Division of Insect Systematics, ICAR- NBAIR, Bangalore for identification of parasitoid.

\section{References}

1. Galindo-Cardona A, Achar JD, Gonzalez-Brizuela G, Eduardo Martin E, Salvo SA, Monmany-Garzia AC. First report and molecular determination of Apanteles galleriae Wilkinson (Hymenoptera, Braconidae), a parasitoid of the lesser wax moth Achroia grisella F. (Lepidoptera, Pyralidae) in Northwest Argentina. Journal of Apicultural Research 2019;58(4):550-552.

2. Hanumanthaswamy BC, Venkatesh H, Nagaraja MV. Influence of different species of honey bee combs on the life stages and biological parameters of greater wax moth, Galleria mellonella L. Karnataka Journal of Agricultural Sciences 2009;22:670-671.

3. Hanumanthaswamy BC, Rajagopal D. Natural enemies of Greater Wax Moth Galleria mellonella Linnaeus in honey bee colonies. International Journal of Current Microbiology and Applied Science 2017;6(8):3418-3421.

4. Kwadha CA, Ong'amo GO, Ndegwa PN, Raina SK, Fombong AT. The biology and control of the Greater
Wax Moth, Galleria mellonella. Insects 2017, 8(61).

5. Paddock FB. The bee moth or wax worm. Texas Agricultural Experiment Station; USA. 1918, 44.

6. Shimamori K. On the biology of Apanteles galleriae, a parasite of the two species of wax moths. Honeybee Science. 1987;8:107-112.

7. Subash Chander. Biocontro of wax moths with Apanteles galleriae Wilkinson. Doctoral thesis- Himachal Pradesh Erishi Vishvavidyalaya, Palambur (H.P).1995, 46-50.

8. Verma SC, Desh Raj. Population dynamics of wax moth and their parasitization by A. galleriae Wilk in Apis cerana colonies. Paper presented at the Naional Conference of Apiculture, Bangalore 1997.

9. Vinay Kumar. Development of eco-friendly management of greater wax moth, Galleria mellonella in stored honey bee comb. M. Sc thesis- G. B. Pant University, Uttarkhand 2019, 108-110.

10. Whitfield JB, Cameron SA, Rami'rez SR, Roesch K, Messinger S, Taylor OM et al. Review of the Apanteles Species (Hymenoptera: Braconidae) attacking lepidoptera in Bombus (Fervido bombus) (Hymenoptera: Apidae) colonies in the New World, with Description of a new species from South America. Annals of the Entomological Society of America 2001;94(6):851-857. 